\title{
PROGRAMA DE DOCUMENTACIÓN, CONSERVACIÓN Y VALORACIÓN DE LA FLORA NATIVA DE LA UNIVERSIDAD NACIONAL DEL LITORAL
}

\author{
Pensiero, J. F. ${ }^{1}$
}

\begin{abstract}
RESUMEN
Se presenta una síntesis de las acciones que se realizan en el marco del Programa de Documentación, Conservación y Valoración de la Flora Nativa, declarado de Interés Institucional por la Universidad Nacional del Litoral.
\end{abstract}

Palabras clave: PRODOCOVA, Flora natíva, Recursos fitogenéticos.

\begin{abstract}
Documentation, conservation and valuing program of the native flora of the Universidad Nacional del Litoral.

A summary is presented of the actions carried out in the Program of Documentation, Conservation and Valuation of Native Flora, declared of Institutional Interest by the National University of Litoral.
\end{abstract}

Key words: PRODOCOVA, Native flora, Genetic resources.

1.- ICIAGRO Litoral, UNL-CONICET-FCA. Kreder 2805. 3080HOF, Esperanza, Santa Fe, Argentina. Email: jfpensi@fca.unl.edu.ar

Manuscrito recibido el 14 de abril de 2020 y aceptado para su publicación el 4 de junio de 2020.

Pensiero, J. F. Programa de Documentación, Conservación y Valoración de la Flora Nativa de la Universidad Nacional del Litoral. FAVE - Ciencias Agrarias 20 (1): 11-17. CC BY-NC-SA 4.0 


\section{J. F. Pensiero et al.}

En las últimas décadas se ha reconocido a la diversidad biológica como patrimonio de la humanidad y los países que la poseen deben implementar medidas de protección a través de diversas estrategias de conservación in situ y ex situ y de minimizar su reducción debido a las actividades antrópicas (Convenio de Diversidad Biológica, 1992). En Argentina, producto de la política expansionista que conlleva el modelo agrícola, basado principalmente en el monocultivo, importantes áreas ricas en diversidad biológica se vieron seriamente modificadas, empobrecidas y algunas eliminadas. No obstante, quedan aún en el territorio nacional como en el provincial, importantes áreas que poseen una rica diversidad biológica, y particularmente florística, que es prioritario estudiar y preservar antes que sean erosionadas. La Universidad Nacional del Litoral ha demostrado no ser ajena a esta situación, desarrollando acciones en diferentes programas/proyectos institucionales, siendo una de ellas el Programa que se presenta, fomentando la conservación de nuestros recursos naturales y aportando las bases conceptuales y metodológicas necesarias para conservar, valorar y manejar en forma sustentable las especies vegetales nativas.

Un papel importante de la biodiversidad, y en especial de la flora nativa, es su contribución en la provisión de servicios ambientales. No obstante, la erosión genética a la que son sometidas dichas especies, fruto de la degradación de los ecosistemas, el escaso conocimiento que mayoritariamente tenemos de ellas en cuanto a sus aportes ecosistémicos, y a sus potenciales valores como recursos fitogenéticos para la agricultura y ganadería, además de otros usos factibles como alimenticias, forestales, forrajeras, medicinas, insecticidas, industriales, cosméticos, etc., son causas suficientes para iniciar acciones que permitan documentar, conservar y valorar dichos recursos. Estas acciones se deben realizar a través de colecciones de especímenes (en herbarios), la conservación in situ (en áreas protegidas) y ex situ (en bancos de germoplasma) y la valoración de sus potencialidades a través de proyectos específicos de I+D.

Si bien en Argentina habitan 10.221 especies de plantas vasculares, de las cuales 7.506 son nativas y 1.731 son endémicas (Zuloaga et al. 2019), no existe una política de estado clara y a largo plazo que se oriente a la conservación y valoración de nuestros recursos naturales, a pesar que en esta diversidad florística existen numerosas especies con potencial como recursos fitogenéticos. En relación con esto, son escasas las acciones que se han realizado, y las mismas han sido desarrolladas por instituciones o investigadores de manera aislada y con escaso apoyo y financiamiento estatal. Dos ejemplos que ilustran lo dicho lo constituyen el Banco Nacional de Germoplasma de Prosopis $^{1}$ de la Facultad de Ciencias Agropecuarias de la Universidad Nacional de Córdoba, y la colección de especies del género Paspalum que posee la Facultad de Ciencias Agrarias de la Universidad Nacional del Nordeste (Dr. Quarín, comunicación personal).

$\mathrm{El}$ valor que poseen algunas de nuestras especies nativas ha sido reconocido por investigadores extranjeros, lo que se refleja en las colecciones que de ellas se conservan en bancos de germoplasma del exterior, incluso de especies endémicas de nuestro país. Por esto, con la intención de desarrollar este aspecto de vacancia y en conocimiento de las cualidades que presentan va-

1.- http://www.agro.unc.edu.ar/ paginafacu/servicios/germo/index.html 
rias especies nativas de nuestro país, y con el propósito de generar un espacio físico y cognitivo de referencia para el conocimiento, conservación y valoración de la flora nativa, tomando como epicentro el área de influencia de nuestra región, se crea en setiembre de 2011, bajo la resolución 383 del Consejo Superior de la Universidad Nacional del Litoral, el Programa de Documentación, Conservación y Valoración de la Flora Nativa, declarándolo además, de Interés Institucional de nuestra Universidad.

Según la resolución de su creación, el Programa depende de Rectorado a través de las Secretarías de Vinculación Tecnológica y Desarrollo Productivo (actual Secretaría de Vinculación y Transferencia Tecnológica), Extensión (actual Secretaría de Extensión Social y Cultural) y Ciencia y Técnica (actual Secretaría Ciencia, Arte y Tecnología). Su estructura de gestión está constituida por un Director (designado por el Rector) y un Comité Ejecutivo (integrado por dos representantes de la Facultad de Ciencias Agrarias, y los Secretarios de las secretarías participantes). Son objetivos generales del Programa:

- Documentar la flora nativa de Argentina y de la provincia de Santa Fe en particular en el Herbario “Arturo E. Ragonese”.

- Conservar la flora nativa de Argentina y de la provincia de Santa Fe en particular que se considere potencialmente valiosa en el Banco de Germoplasma.

- Caracterizar aquellas especies nativas priorizadas por sus cualidades.

- Diseñar y desarrollar actividades de formación relacionadas con la documentación, conservación y caracterización de la flora nativa.

- Brindar a la comunidad la información sobre las especies documentadas y conservadas.
A continuación, se presenta una síntesis de las acciones que se desarrollan en el marco del Programa.

\section{Documentación}

\subsection{Herbario “Arturo E. Ragonese"}

Los fundamentos de la creación del Programa se sustentan en las acciones realizadas por docentes-investigadores de la FCA a partir de la década del 80, iniciándose en este período un importante y arduo trabajo de recolección y documentación de la flora, primero provincial y luego regional. Dichas colecciones, adecuadamente acondicionadas y clasificadas, se conservan en el Herbario "Arturo E. Ragonese”, depositado en la Facultad de Ciencias Agrarias, constituyendo el centro de referencia de la flora provincial y un importante patrimonio de la Universidad Nacional del Litoral. Dicho herbario, reconocido internacionalmente bajo la sigla "SF” (inscripto en el Index Herbariorum -registro internacional de colecciones botánicas-), es el más grande que posee la provincia de Santa Fe y su colección, totalmente informatizada, forma parte del Sistema Nacional de Datos Biológicos del Ministerio de Ciencia, Tecnología e Innovación y está integrada, además, a las colecciones de Flora Argentina (http://ww. floraargentine.edu.ar).

El Herbario fue creado en el año 1935 por el Ingeniero Agrónomo Arturo E. Ragonese (1909-1993), en la Estación Experimental Ángel Gallardo, perteneciente al entonces Instituto Experimental de Investigaciones y Fomento Agrícolo-Ganadero de la provincia de Santa Fe (hoy Ministerio de la Producción). Al Ing. Ragonese se deben las primeras colecciones botánicas realizadas en la provincia y conservadas en un herbario local. Al poco tiempo, en el año 1938, se suma al equipo de técnicos de Án- 
gel Gallardo el Ingeniero Agrónomo Guillermo Covas, quien participó con Ragonese en numerosas expediciones botánicas en la provincia. Dicho Herbario tuvo un crecimiento importante hasta mediados de la década del 40 , momento en el que, por diversos motivos, ambos técnicos se alejan de la provincia de Santa Fe. Sin técnicos interesados en la flora nativa, desde el año 1945 y hasta fines de la década del 70, el Herbario interrumpió su actividad y fue abandonado, sufriendo los avatares de varios traslados. A fines de la década del 70, a través de gestiones realizadas por la entonces Facultad de Agronomía y Veterinaria de la Universidad Nacional del Litoral (FAVE), el Herbario es donado a dicha Facultad. En el año 1983, el Consejo Directivo de la entonces FAVE nombra un Curador responsable del Herbario, iniciándose a partir de entonces un período de recuperación y crecimiento de las colecciones botánicas en la provincia. El Herbario original que fuera recibido con unos 2.500 especímenes, en la actualidad cuenta con aproximadamente 25.000 ejemplares. En su colección están representadas un total de 2.532 especies correspondientes a 1.052 géneros y 194 familias de plantas. Si bien gran parte de la colección corresponde a la flora de la provincia de Santa $\mathrm{Fe}$, se conservan plantas colectadas en viajes realizados a distintas provincias desde Formosa a Río Negro y Neuquén. Se cuenta además con colecciones correspondientes al NE de Paraguay, N de Brasil y SE de Bolivia. En el Herbario se documenta el 95 \% de la flora vascular de la provincia de Santa $\mathrm{Fe}$, ya que conserva 1.897 especies de las 1.969 que posee la provincia (Pensiero et al. 2005).
Esta vasta y rica colección documenta, además de la flora provincial y regional, numerosos trabajos técnico-científicos relacionados con estudios taxonómicos, florísticos, de vegetación, sobre plantas tóxicas, malezas y de forrajeras nativas, que se han desarrollado en 80 años. Esta colección ha servido, en forma directa o indirecta, a la publicación de más de 100 trabajos científicos y al desarrollo de numerosas tesis de posgrado.

\subsection{Banco de Imágenes IRUPÉ}

El Banco de imágenes "IRUPÉ” (https:// www.fca.unl.edu.ar/prodocova/IRUPE/irupe.html), contiene unas 32 mil imágenes fotográficas correspondientes a la flora de Argentina, y relaciona 8.000 nombres vulgares con 4.187 nombres científicos, posibilitando de este modo la búsqueda tanto por nombres científicos de las especies como por sus nombres vulgares (Ver Paye et al., 2021 en este número).

Este banco incluye imágenes de 2.250 especies correspondientes a 1.036 géneros y 182 familias, además de 2.913 imágenes de los tipos de vegetación característicos de cada ecorregión de Argentina.

A diferencia de otros bancos de imágenes, este se distingue por: a) cada imagen va acompañada por un set de datos relativos al lugar, fecha y crédito fotográfico, b) permite acceder a las imágenes y nombres científicos de las especies a través de la consulta por un nombre vulgar, y c) las especies fotografiadas están documentadas por un ejemplar de herbario que se conserva en el Herbario "Arturo E. Ragonese”. 


\section{Conservación}

\subsection{Conservación in situ de la flora nativa}

La conservación in situ de la vegetación y flora nativa ha sido canalizada a través de distintas acciones. Se realizaron trabajos de relevamiento de la vegetación y flora de las dos reservas que posee la Universidad Nacional del Litoral, la Reserva Ecológica Costanera Este de la Ciudad Universitaria (Kiverling, 2000) y de la Reserva Ecológica "Med. Vet. Martín Rodolfo de la Peña” de la Escuela de Agricultura, Ganadería y Granja (Exner et al., 2004).

Se ha participado en distintos proyectos relacionados con el manejo sustentable de nuestros recursos florísticos, tales como a) "Alternativas de sustentabilidad del bosque nativo del Espinal”. Proyecto PIARFON (Proyecto de Investigación Aplicada a los Recursos Forestales Nativos), realizado entre la Facultad de Ciencias Agropecuarias de la Universidad Nacional de Entre Ríos, Facultad de Ciencias Agropecuarias de la Universidad Nacional de Córdoba y la Facultad de Ciencias Agrarias de la Universidad Nacional del Litoral. Financiado por la Secretaría de Ambiente y Desarrollo Sustentable del Ministerio de Salud de la Nación, en el Marco de Proyecto de Bosques Nativos y Áreas Protegidas BIRF 4085 AR (2004-2007). b) “Acciones para el manejo sustentable del bosque nativo del Espinal y desarrollo local en comunidades rurales del departamento San Javier (Provincia de Santa Fe)”. Proyecto del Programa Social de Bosque (ProSoBo): (2007-2010).

Por otra parte, se ha participado activamente en distintos espacios interinstitucionales relativos conservación y manejo sustentable de los recursos naturales de la provincia. A modo de ejemplo se mencionan: a) Mesa Agroforestal Santafesina, b)
Comité Intersectorial de Maneo del Sitio Ramsar “Jaaukanigás”, c) Consejo Consultivo de Bosque Nativo, d) Equipo Técnico Forestal Interinstitucional.

\subsection{Conservación ex situ}

En el año 2003 se inicia en la Facultad de Ciencias Agrarias un programa de colecta y caracterización de recursos forrajeros nativos a través de un trabajo interdisciplinario. En forma casi simultánea, junto con la creación por parte de UNL del Programa de Documentación, Conservación y Valoración de la flora nativa, el Consejo Directivo de la FCA crea el Banco de Germoplasma "Ing. Agr. José Mario Alonso" (https:// www.fca.unl.edu.ar/prodocova/germoplasma.xhtml). Dicho banco, el primero en la provincia de Santa Fe, tiene como objetivo conservar germoplasma de recursos fitogenéticos nativos presentes en la provincia de Santa Fe en particular y de la región en general. En tal sentido, desde el punto de vista utilitario, el germoplasma conservado tiene por objetivo disponer de variabilidad genética para encarar diferentes estrategias de introducción a cultivo o enriquecimiento de ambientes naturales degradados. Para el desarrollo del banco fue de suma importancia la colaboración recibida por parte del Ministerio de la Producción del gobierno de la provincia de Santa Fe en el año 2018, que posibilitó la adquisición y puesta en funcionamiento de la cámara frigorífica donde se conservan las semillas.

Este Banco de Germoplasma de la FCAUNL es el único que posee la provincia de Santa Fe y uno de los pocos que conserva especies nativas de Argentina, y si bien en un principio las colecciones estuvieron orientadas a la recolección y conservación de especies con potencial forrajero, a me- 
dida que se fueron sumando otras líneas de trabajo e investigación, las colectas del Banco se ampliaron a especies que poseen potencial como frutales, forestales, ornamentales, paisajísticas y apícolas.

En la actualidad el Banco cuenta con una colección de 565 entradas (Ver Zabala et al., 2021 en este número).

\section{Valoración}

El objetivo que se persigue en relación con la valoración de la flora nativa es, en principio, generar conocimientos en relación a los recursos fitogenéticos priorizados y al mismo tiempo resaltar sus potencialidades, y que, en la medida de lo posible, esa puesta en valor genere algún desarrollo tecnológico. Los conocimientos básicos y aplicados que se han generado en las especies estudiadas han permitido la publicación de numerosos artículos científicos, y en algunos casos, iniciar acciones relativas al desarrollo tecnológico a través de distintas vinculaciones y transferencias tecnológicas.

Un ejemplo claro de ello, pilar importante del programa, fue el trabajo realizado con algunas especies forrajeras nativas y naturalizadas, en las que luego de varios años de trabajo interdisciplinario, y con la participación además, de pequeños productores y empresas, se logró, a través de varios convenios de vinculación y transferencia tecnológica, inscribir ante el INSE 8 cultivares forrajeros, 3 de ellos correspondientes a una especie naturalizada (Melilotus albus 'Yachay', 'Munay' y 'Faraón') y los restantes a especies nativas (Macroptilium lathyroides 'Mancebo', Macroptilium erythroloma 'Don Augusto', Desmanthus virgatus 'DV7059', Desmanthus leptophylus 'DLBT' y Elymus scabrifolius 'El Triunfo'). Los cultivares 'Faraón' y 'El
Triunfo' se desarrollaron en forma conjunta con la Facultad de Agronomía (UBA).

Para el desarrollo de estos cultivares se firmaron distintos Convenios de Vinculación Tecnológica con empresas semilleras: Cereagro S.A., Gentos S.A. y Peman \& Asociados SA, y con la Asociación de Pequeños Productores de Alejandra y Zona (APPAZ), esta última para el desarrollo de esquemas de producción de semillas de forrajeras nativas mejoradas en campos de pequeños productores.

\section{Formación de recursos humanos}

Un aspecto importante del Programa lo constituye la formación de recursos humanos, en tal sentido, en temas relacionados con el mismo se han desarrollaron 2 tesis de maestrías, 11 tesis doctorales, 2 de ellas en ejecución, se obtuvieron 20 becas de CONICET y han participado numerosos alumnos y graduados el calidad de adscriptos.

Por otra parte, en el marco del programa se dicta el curso de posgrado "Conservación y uso de recursos fitogenéticos nativos”, uno de los primeros sobre esta temática dictado en nuestro país, y en el que han participado más de 100 profesionales de distintas provincias argentinas.

\section{Reconocimiento nacional}

El trabajo desarrollado en el marco del PRODOCOVA fue reconocido y valorado a nivel nacional, recibiendo en el año 2018 el premio "Fidel A. Roig 2017", que distingue la trayectoria científico-tecnológica de grupos de investigación de Argentina que hayan participado activamente en el desarrollo de iniciativas vinculadas al uso sustentable y/o a la conservación de la biodiversidad. 


\section{BIBLIOGRAFÍA}

Convenio sobre Diversidad Biológica. 1992. Secretaría del Convenio sobre Diversidad Biológica. Programa de las Naciones Unidas para el Medio Ambiente.

Exner, E.; C. H. D’Angelo \& J. F. Pensiero. 2004. Vegetación y flora de la reserva universitaria de la Escuela Granja de Esperanza (Santa Fe, Argentina). Revista FAVE, Ciencias Agrarias 3 (1-2): 53-76.

Index Herbariorum: A Global Directory of Public Herbaria and Associated Staff. New York Botanical Garden's Virtual Herbarium. (http://sweetgum.nybg.org/science/ih/)

Kiverling, M. A. 2000. Flora Fanerogámica de la Reserva Ecológica de la ciudad universitaria Paraje "El Pozo". Tesina de Licenciatura en Biodiversidad. Fac. de Humanidades y Ciencias, Univ. Nac. del Litoral, Santa Fe. 275 pp.
Paye IA, Pensiero JF, Grenon DA, Exner E. 2021. IRUPÉ: Sitio web de imágenes de la flora nativa de Argentina asociada al herbario SF. Revista FAVE, Secc. Cs. Agrarias.

Pensiero, J. F.; H. F. Gutiérrez; A. M. Luchetti; E. Exner; V. Kern; E. Brnich; L. Oakley; D. Prado \& J. P. Lewis. 2005. Flora vascular de la provincia de Santa Fe. Claves para el reconocimiento de las familias y géneros. Catálogo sistemático de las especies. 403 pp.

Zabala JM, Exner E, Cerino C, Buyatti M, Cuffia C, Marinoni L, Kern V, Pensiero JF. 2021. Recursos fitogenéticos forestales, forrajeros, de interes apícola y paisajístico nativos de la província de Santa Fe (Argentina). Revista FAVE, Secc. Cs. Agrarias.

Zuloaga FO, Belgrano M, Zanotti CA. 2019. Actualización del catálogo de las planas vasculares del Cono Sur. Darwiniana, nueva serie $7(2): 208-278$. 